\title{
Variant Anatomy of Renal Vein and Its Intra- Organ Branches
}

\author{
Kafarov E.S. ${ }^{1, *}$ Zenin O.K. ${ }^{2}$ Fyodorov S.V. ${ }^{3}$ Bataev Kh.M. ${ }^{4}$ Vezirkhanov A.Z. ${ }^{1}$ \\ ${ }^{1}$ Department of Normal and Topographic Anatomy with Operational Surgery, Chechen State University, Grozny, Russia \\ ${ }^{2}$ Department of Human Anatomy, Penza State University, Penza, Russia \\ ${ }^{3}$ Department of Surgery with Endoscopy and Stationary Replacement Technologies, Bashkortostan State Medical \\ University of the Ministry of Health of Russia, Ufa, Russia \\ ${ }^{4}$ Department of Intermediate Level Therapy, Chechen State University, Grozny, Russia \\ *Corresponding author. Email: Edgar-kafaroff@yandex.ru
}

\begin{abstract}
The purpose of the study is to analyze the variant anatomy of renal veins forming its venous vessels and inflows. In total, 142 corrosion casts of the human kidney venous system were produced followed by 3D stereomorphological analysis to identify the sources of renal veins forming its venous vessels and inflows. It is revealed that in general the main renal vein is formed at a fusion of two $(57.8 \%)$ or three $(31.0 \%)$ venous inflows with statistical significance $\mathrm{p} \leq 0.05$. In cases of renal vein formation from two venous inflows, in $32.4 \%$ of cases it is upper and lower pole venous inflows, and in $25.4 \%$ - dorsal and ventral venous inflow. In cases when the renal vein is formed from three venous inflows in $15.5 \%$ of cases it is central, upper pole and lower pole venous inflows, in $8.4 \%$ of cases it is upper pole, lower pole and dorsal central venous inflows and in $4.2 \%$ of cases it is lower-pole, ventral and dorsal venous inflows. The frequency of other options of the main renal vein formation did not exceed $5 \%$ of cases. The studies also showed the individual variability of angioarchitecture of the venous kidney system as a whole, namely the presence of various links, the variability of which depends not only on the formation of renal vein from the corresponding venous inflows, but also on the types of scattered or main fusion of intra-organ venous inflows, on which the level of drainage abilities of the entire venous kidney system will also depend.
\end{abstract}

\section{Keywords: kidney, venous channel, variant anatomy}

\section{INTRODUCTION}

The renal arterial system has been the subject of many anatomical studies, statistical analysis and descriptions $[5,6,11,15-20]$. However, the renal vein anatomy lacks similar exhaustive study. Modern surgical and radiological methods dictate the need to reassess and determine the anatomy of renal veins [7-9]. In this regard, the role of primary inflows of the renal vein and their association with renal artery branches and renal hilum is important. Besides, confusion in nomenclature with respect to renal veins makes it difficult to determine the quantity, exact type and source of their origin $[4,9,10]$.

Variations in structure and organization of renal veins are described in some scientific papers, but do not have a holistic unified approach. Thus, according to the ultrasonographic analysis, the number of veins directly associated with the formation of renal veins varies from 3 to 4, and in some cases reaches higher number [9].

One of the researchers named the branches of renal vein origin as initial segmental vessels [13]. According to this author, they are involved in the outflow of all renal parenchyma as well as upper excretory ducts. The main renal veins are formed by joining the interlobar (segmental) veins [2]. According to the author, the interlobar veins and arteries form vascular pedicles of renal segments, which can easily be secured at the place of their entry into the kidney.

In their studies on the corrosion casts of renal veins, one of the authors found that the abdominal and dorsal veins forming the renal vein are often located at the renal hilum [3].

According to the works of several authors, primary venous inflows forming the renal vein take a direct part in venous outflow from the kidney and create I, II, III, IV types of venous system of human kidneys [4].

The following types of renal veins were identified by one of the authors as a result of a selective-decomposition study of the corrosion casts of kidney veins: main vein, ventral and dorsal; upper and lower pole (ventral vein inflows); segmental or interlobar (inflows of pole and dorsal veins) and parapyramid (inflows of segmental veins) [1].

A number of researchers studied arterial and venous kidney systems using injection corrosion techniques. According to the authors of the study, while fusing the veins of adjacent renal lobes form segmental veins, which along with segmental arteries pass through renal poles. In the zone of renal papillae, segmental veins come out of 
parenchyma and go into the intrarenal groove (sinus), where they connect to each other and form a renal vein [10].

The analysis of literature reveals some misrepresentation regarding the sources of renal veins formation, their number and names, which became the purpose of this study.

\section{METHODS AND MATERIALS}

The material for the study included 142 kidneys of people in the age category from 22 to 90 , who died from diseases unrelated to renal pathology. Anatomic dissection was performed on the material under study. Next, corrosion casts of the venous kidney system were made, for which the fast-acting polymers Redont-3, Styracryl and Protacryl were used. Three-dimensional stereomorphological analysis of corrosion samples was then performed to identify the sources of formation of renal veins, its venous vessels and inflows, as well as their variations with respect to sagittal, frontal and horizontal planes. The resulting tool and digital analysis data were processed using variation statistics techniques based on a workstation with an Intel Core2Duo T5250 $1.5 \mathrm{GHz}$ processor, RAM up to $2 \mathrm{~Gb}$, Windows 7. The Excel for Microsoft Office 2007 was used.

\section{RESULTS}

The results of this study show that in 82 corrosion casts of renal veins (57.8\% of cases), the formation of the main renal vein occurs when the two veins join each other. Of these, $25.4 \%$ (36 corrosion casts) of the renal vein is formed from the anterior and posterior venous inflows. In the remaining $32.4 \%$ of cases (46 corrosion casts), the formation of the main renal vein is detected by joining the upper and lower pole venous inflows.

In $31.0 \%$ of cases (44 corrosion casts) the formation of the main renal vein from three venous inflows was found. In 22 corrosion casts $(15.5 \%)$ the renal vein is formed by the fusion of upper, lower pole and central venous inflows. In $8.5 \%$ of cases (12 corrosion casts) the formation of the main renal vein from the dorsal central, upper pole and lower pole veins is observed. In other 6 corrosion casts (4.2\% of cases) it is formed from ventral, dorsal and lower pole veins. With respect to gender and body side, in men, when the right renal vein was formed from ventral, dorsal, and lower pole venous inflows, all intra-organ veins had a disjoint type of inflow fusion, which was found in $2.8 \%$ of cases, and in the left renal vein formation - in $2.1 \%$ of cases. We found this variant of intra-organ venous inflows in women in $1.4 \%$ of cases on both sides.

According to the study, the formation of the main renal vein with perforating inflows is found in $4.2 \%$ of cases. Moreover, three options of renal vein formation have the same frequency $-1.2 \%$. In the first option the renal vein is formed from upper pole, lower pole perforating, front and rear venous inflows. In the second - from upper pole, lower pole, dorsal perforating and central venous inflows. In the third option there is one stem with perforating venous inflows.

The main renal vein formed from the upper pole, anterior and posterior venous inflows occurs only in 2 corrosive casts (1.4\% of cases). In $2.8 \%$ of cases (4 corrosion casts), the renal vein is formed when front lower pole, front upper pole, and rear central perforating venous inflows join together. With respect to gender and body side, in men, when the right renal vein is formed from anterior, posterior, and upper pole venous inflows, all intraorgan veins had a disjoint type of vein fusion, which was met in $0.7 \%$ of cases, regardless of the body side. Such conneciton of intra-organ inflows was not found in women.

The study also showed that in $25.4 \%$ of cases the left renal vein is formed by dorsal and ventral venous inflows (anterior and posterior). Moreover, each vein is formed of fan-shaped 3-order veins joining each other, between which an extrarenal pelvis was located. With respect to gender and body side the studies showed that when the right renal vein was formed from ventral and dorsal venous inflows in men, both of these inflows had a disjoint type of fusion, which was found in $6.3 \%$ of cases, and the left renal vein - in $9.1 \%$ of cases. In women, in both kidneys, in the same option of renal vein formation, both of these inflows had a disjoint type of fusion, which was found in $4.9 \%$ of cases. In men, under this option of renal vein formation, the ventral venous inflow had a disjoint type of fusion of intra-organ inflows, and the dorsal main, which was found in $0.7 \%$ of cases on both sides. In women this option of fusion of intra organ venous inflows was observed only on the right - in $1.4 \%$ of cases.

It is known that the topographic features of renal hilum are determined by the localization and shape of the pelvis. The extrarenal pelvis is wrapped with venous inflows at the front and rear. Besides, venous inflows in renal hilum are often located outside the organ.

In $32.4 \%$ of cases (46 corrosion casts) the upper and lower pole veins join when leaving the renal hilum to form the main renal vein. Besides, the lower pole vein is formed by the fusion of venous inflows of the 3rd order, which remove blood from the central and lower parts of the kidney. The upper pole is from venous inflows that remove blood from the central and upper sections.

It is important to differentiate the upper and lower pole veins, from which the main renal vein is formed. Thus, at a frequency of $56.4 \%$ of cases the upper and lower pole veins are formed by joining the 3rd order front and rear veins. In $28.7 \%$ of cases the upper pole vein is formed by venous inflows draining the dorsal side of the lower pole and the upper pole, and the lower pole vein - from the inflows draining the lower pole of the kidney.

Thus, double drainage from the lower pole of the kidney occurs. In $14.9 \%$ of cases, the lower pole vein drains the posterior surface of the kidney, whereas the upper pole is involved in the drainage of the parenchyma of the anterior surface of the kidney and the posterior part of the upper pole. 
With respect to gender and fusion types of these venous inflows the studies showed that in men, when forming the right renal vein from the upper pole and lower pole venous inflows, both of these vessels had a disjoint type of venous inflow fusion, which occured in $6.3 \%$ of cases, and in the left renal vein - in $7.0 \%$ of cases.

In women with the same option of renal vein formation in the right kidney both of these vessels had a disjoint type of fusion of intra-organ venous inflows, which was typical for $7.0 \%$ of cases, and in the left kidney - in $8.4 \%$ of cases. Under the same option of renal vein formation in men in the right kidney, the upper pole vein basin had the main type of intra-organ inflow fusion, and the lower pole basin had a disjoint type of intra-organ inflow fusion, which was identified in $0.7 \%$ of cases. No intra-organ venous inflows were found in the left kidney of this type of fusion. In women, by contrast, only in the left kidney we revealed this type of fusion of intra-organ venous inflows, which was found in $0.7 \%$ of cases.

In 44 corrosion casts of this study, which is $31.0 \%$ of the cases, renal vein formation is observed from three large venous inflows. Of these, in $15.5 \%$ of cases it is formed by the fusion of upper pole, lower pole and central venous inflows. At the same time, the upper pole venous inflow is formed by veins of the upper pole and part of veins of the central part; while the central - from veins of the central part and lower pole vessel - from lower pole veins. With respect to gender and body side, in men, when the main renal vein was formed from the upper pole, central and lower venous inflows, all intra-organ venous vessels had a disjoint type of fusion regardless of the body side, which was observed in $4.2 \%$ of cases. Under the same option, in women, intra organ venous inflows also had a disjoint type of fusion, regardless of the body side, which was observed in $4.2 \%$ of cases.

Later, in 12 corrosion casts ( $8.5 \%$ of cases) the main renal vein is formed when the dorsal central, upper and lower pole venous inflows join together. At the same time, the ventral location of upper pole vein relative to pelvis is observed with the drainage of the central part and upper pole of the kidney. As for the lower pole vein, its location was also ventral with respect to pelvis with inflows from the lower pole and the central kidney. The dorsal central vein was placed dorsally from pelvis draining the posterior surface of the kidney. With respect to gender and body side, in men when the main renal vein is formed from the upper pole vein, lower pole and dorsal central vein, all intra organ venous inflows had a disjoint type of fusion, which was observed in $2.8 \%$ of cases regardless of the body side. In the same option of renal vein formation, in women the intra organ venous inflows of both kidneys had a disjoint type of fusion, which was revealed in $2.1 \%$ of cases. In another option of the formation of the main renal vein from the same vessels, the upper pole and lower pole veins had a disjoint fusion type of intra organ venous inflows, and the dorsal central - main fusion type, which was found on the right in $1.4 \%$ of cases. This option of the fusion of intra organ inflows in the left kidney was not found. In women, this type of fusion of intra organ venous inflows was observed in $0.7 \%$ of cases in both kidneys.
In 10 corrosion casts ( $7.0 \%$ of cases) the participation of four large venous inflows was observed in the formation of the main renal vein: central, lower pole, dorsal central, ventral upper. At the same time, the ventral upper pole venous inflow takes part in the outflow from the upper pole and the central renal part, and the lower pole - from the lower pole part. Then, the dorsal central venous inflow has a dorsal direction relative to pelvis and drains the dorsal central kidney region. In $4.2 \%$ of cases, which is 6 corrosion casts, the formation of renal vein occurs when the lower pole, rear and front venous inflows join together. The anterior venous inflow was involved in draining the anterior upper kidney and the posterior venous inflow was involved in draining the posterior upper renal parenchyma. At the same time the lower pole venous inflow removes blood from the lower pole of the kidney.

In $2.8 \%$ of cases, the formation of the main renal vein from the posterior central probing, anterior upper pole, and anterior lower pole large venous inflows was observed. At the same time the upper pole and lower pole venous inflows were located ventrally relative to pelvis and drained, respectively, the upper pole, the central part, the lower pole and the central part of the kidney. The posterior central perforating inflow was directed along the dorsal side of the pelvis and drained the parenchyma of the posterior kidney surface. In two corrosion casts $(1.4 \%$ of cases), the renal vein was formed by the fusion of upper pole, front and rear venous inflows. The posterior and anterior venous inflows drain the dorsal and ventral surfaces of the lower kidney pole, while the upper pole inflow drains the upper pole parenchyma.

In 6 corrosion casts, which is $4.2 \%$ of cases, the renal vein is formed involving perforating venous inflows. Two options were identified with the same frequency $(1.4 \%)$ : in the first option the renal vein is formed from the upper pole, central, dorsal perforating and lower pole venous inflows, and in the second option is formed from the upper and lower pole perforating, ventral and dorsal venous inflows. At the same time, the central venous inflow drained the central kidney areas, the upper pole inflow drained the upper pole and part of the central area, and the lower pole - the lower pole of the kidney. Then, the dorsal perforating venous inflow was behind the pelvis and participated in the drainage of the posterior-central part of the renal parenchyma. In $1.4 \%$ of cases, the main renal vein represented a long single stem with a large number of small perforating venous inflows.

\section{CONCLUSION}

The stereoanatomic analysis of renal veins on corrosion casts shows that the formation of the main renal vein with a frequency of $91.6 \%$ of cases corresponds to nine main established options.

Depending on the localization and topography of venous inflows in the renal hilum, as well as the direction of large arteries, these vessels were given names according to the International Anatomical Nomenclature (2003): ventral, dorsal, upper pole, lower pole, central, etc. 
Besides, it was found that mainly the main renal vein is formed by the fusion of two $(57.8 \%)$ or three $(31.0 \%)$ venous inflows. At the same time statistically significant differences were not noted $(\mathrm{p} \leq 0.05)$.

In terms of frequency $(32.4 \%)$ the first option of renal vein formation from two inflows is its formation from the upper pole and the lower pole venous inflows [7, 8].

The upper and lower pole venous inflows and the central venous inflow participated in the formation of the main renal vein from three venous inflows in $15.5 \%$ of cases, in $8.4 \%$ of cases the upper pole, lower pole and dorsal central venous inflows and in $4.2 \%$ of cases the lower pole, ventral and dorsal venous inflows.

The remaining options did not exceed $5 \%$ of cases. In $2.8 \%$ of cases it was formed by ventral (upper pole and lower pole) and dorsal central venous inflows, and in $1.4 \%$ of cases - by upper pole, ventral and dorsal venous inflows.

Some authors refer to the formation of the renal vein by the fusion of segmental venous vessels [2, 14, 19]. However, this study showed that the segmental or interlobar veins are intra-organ (III) units of renal veins and most of them are localized in the parenchyma of the organ and only a small number is found in the renal sinus.

Giannoulia-Karadana and co-authors received similar options of renal vein formation by digital angiography methods, but the results differed in the frequency of occurrence [12]. According to these authors, the study did not find the presence of segmental veins in the kidney due to the lack of isolated venous outflow in kidney segments. However, according to several authors [1, 4], the renal vein is formed by venous inflows and there are segmental venous vessels in the kidney. The results of our study correspond to the data of Giannoulia-Karadana and coauthors who expressed the opinion that there are no segmental veins in kidneys and contradict the research of Azmi Mahmoud Ali Hussein [1, 12].

Thus, it is revealed that generally the main renal vein is formed when two $(57.8 \%)$ or three $(31.0 \%)$ venous inflows join with statistical significance of $p \leq 0.05$. In cases of renal vein formation from two venous inflows, in $32.4 \%$ of cases it is upper and lower pole venous inflows, and in $25.4 \%$ of cases - dorsal and ventral venous inflows. In cases of its formation from three venous inflows in $15.5 \%$ of cases it is central, upper pole and lower pole venous inflows, in $8.4 \%$ of cases - upper pole, lower pole and dorsal central venous inflows and in $4.2 \%$ of cases - lower pole, ventral and dorsal venous inflows. The frequency of remaining options of the main renal vein formation did not exceed $5 \%$ of cases. The studies also showed the individual variability of angioarchitectonics of the venous kidney system as a whole, namely the presence of various links, the variability of which depends not only on the formation of the renal vein from the corresponding venous inflows, but also on the types of scattered or main fusion of intra-organ venous inflows, on which the level of drainage abilities of the entire venous kidney system will also depend.

\section{ACKNOWLEDGMENT}

The paper was published as part of the Russian Foundation for Basic Research grant under contract 18-29-09118.

\section{REFERENCES}

[1] A. Mahmoud, A. Hussein, Venous bed and its sintopic relations with arteries of kidneys, Med. today and tomorrow 2 (2008) 101-104.

[2] M.P. Burykh, Nerves and vessels of human kidneys and some animals, LLC Knowledge, Kharkov, 2000, $230 \mathrm{p}$.

[3] E.S. Valishin, Vascular kidney system, Abstracts of the VI Congress of the International Association of Morphologists, Kazan Medical State University, vol. 121, no. 2, 2002.

[4] K.K. Gubarev, V.V. Musokhranov, M.V. Borisenko, Peculiarities of ureter preparation during kidney transplantation depending on ureter vein arrangement options at different types of renal vein formation, Omsk Sci. Bull. 3(37) ch. III (2006) 231-334.

[5] O.K. Zenin, Human arterial system in numbers and formulas, Donbass, Donetsk, 2002, 196 p.

[6] O.K. Zenin, E.L. Kryukov, D.V. Remizov, Прикладні аспекти морфології. Актуальні аспекти функціональної морфології та інтегративної антропологіï, Materials of scientific and practical conference (20-21 May 2009), Venicy, 2009, pp. 112-114.

[7] E.S. Kafarov, Structural transformations of venous vessels of human kidneys in mature, elderly and old ages, Ph.D. Thesis, Ufa, 2014, 45 p.

[8] E.S. Kafarov, S.V. Fyodorov, I.U. Lechiev, Comparative characteristic of venous vessels of human kidneys according to X-ray angiography and tomography, Morphol. 152(4) (2017) 32-37.

[9] T.A. Kwyatkovskaya, E.H. Chernyavsky, T.L. Kuziak, Anatomical-sonographic comparison of morphometric data of renal vessels and their intraorgan branches, Russ. Morpholog. Bull. 1-2 (2000) 201-202.

[10] Yu.P. Kostilenko, Azmi Mahmoud, Ali Hussein, Angioarchitectonics of medulla and cortex of kidney, Клінічна анатомія та оперативна хірургія 7(4) (2008) 44-48.

[11] P.St. Bordei, D. Antohe, Anatomical study of triple renal arteries, Morpologie 86(274) (2002) 37-41.

[12] A. Giannoulia-Karadana et al., Inferior vena cava and right atrial thrombosis in children with nephroblastoma: diagnostic and therapeutic problems, J. Pediatr. Surg. 35(10) (2000) 1459-1461. 
[13] C. Gillot, Necessity of testing drainage of left renal vein shunts before section, Annales de Chirurgie 27(3) (April 1973) 325-327.

[14] M. Irsutti et al., Mesoblastic nephroma: prenatal ultrasonographic and MRI features, Pediatr. Radiol. 30(3) (2000) 147-150.

[15] E.S. Kafarov, L.A. Udochkina, K.M. Bataev, S.V. Fedorov, Options for the Formation of Renal Human Veins, Int. J. of Engineer. and Advan. Technol. (IJEAT) 8(4) (April 2019). ISSN: 2249-8958.

[16] G.S. Longia, V. Kumar, S.K. Saxena, C.D. Gupta, Surface projection of arterial segments in the human kidney, Acta Anat (Basel) 113(2) (1982) 145-150.
[17] J.F.M. Meaney, Magnetic resonance angiography of the peripheral arteries: current status, Eur. Radiol. 13(4) (2003) 836-852.

[18] K.T.G. Tan, MR angiography of renal artery stenosis, Med. Imag. Int. 13(3) (2003) 21-23.

[19] G.C. Velmahos et al., Angiographic embolization for intraperitoneal and retroperitoneal injuries, World J. Surg. 5 (2000) 539-545.

[20] D. Zahoi, V. Niculescu, Segmentarea renala concept morphologic cu valoare chirurgicala, The IV National Congress of Romanian Society of anatomists and the Congres of the Anatomy Departament of the Medical union of Balcans and Black Sea Countries, Romania, Oradea, 2000, 249 p. 